\title{
PERTUNJUKAN WAYANG TOPENG DUSUN KEDUNGPANJANG, SONEYAN, MARGOYOSO KABUPATEN PATI (Kajian Holistik)
}

\author{
Lailatul Qodriyah \\ Institut Seni Indonesia (ISI) Surakarta \\ Jalan Ki Hadjar Dewantara No. 19 Kentingan, Jebres, Surakarta 57126 \\ Dwi Wahyudiarto \\ Institut Seni Indonesia (ISI) Surakarta
}

\begin{abstract}
Abstrak
Pertunjukan Wayang Topeng di Dukuh Kedungpanjang Desa Soneyan Kecamatan Margoyoso Kabupaten Pati Jawa Tengah merupakan bentuk seni pertunjukan drama tari dengan menggunakan topeng. Pertunjukan ini ada sejak tahun 1896. Cerita yang digunakan di dalam pertunjukan pertunjukan Wayang Topeng ialah Among Tani. Pertunjukan Wayang Topeng digunakan untuk ritual bersih desa pada bulan Besar (penanggalan bulan jawa) hari sabtu kliwon. Permasalahan yang akan diteliti dalam penelitian ini antara lain bagaimana latar belakang penyusunan Pertunjukan Wayang Topeng, bagaimana bentuk Pertunjukan Wayang Topeng, dan tanggapan masyarakat terhadap Pertunjukan Wayang Topeng. Penelitian ini menggunakan metode penelitian kualitatif dengan pendekatan kritik holistik. Untuk mengkaji faktor genetik dan faktor afektif menggunakan pemikiran dari H. B Sutopo. Sedangkan dalam mengupas hal-hal yang berkaitan dengan bentuk Pertunjukan Wayang Topeng menggunakan teori bentuk dari Maryono. Adapun Tahap penelitian yang dilakukan dengan cara studi pustaka, wawancara, dan observasi.
\end{abstract}

Kata kunci: Wayang Topeng, Dukuh Kedungpanjang, Kritik Holistik.

\section{Abstract}

Wayang Topeng performance in Kedungpanjang subvillage Soneyan Village, Margoyoso Subdistrict, Pati Regency, Central Java. Constitut the performance of theater dance with use the mask this performance since in 1896. The story that to used on the Wayang Topeng Performance is Among Tani. The Wayang Topeng Performance to used to bersih desa ritual on Besar month at Kliwon Saturday. The problem of this research it is how is Wayang Topeng compose background, how is Wayang Topeng Performance form, and how is society reaction about Wayang Topeng. This research use qualitative research method with critic holistic approach. To review the genetic factor and afective factor use thought of $H$. B Sutopo. To describe the things that related with Wayang Topeng Performance form use theory from Maryono. The step of research did with literature review, interview and observation.

Keywords: Wayang Topeng, Kedungpanjang subvillage, critic holistic. 


\section{PENDAHULUAN}

Pertunjukan Wayang Topeng di Dukuh Kedungpanjang, Desa Soneyan, Kecamatan Margoyoso, Kabupaten Pati, Jawa Tengah merupakan bentuk seni pertunjukan drama tari dengan menggunakan topeng. Adapun pengertian wayang topeng menurut Ensiklopedi Tari Indonesia disebutkan bahwa wayang topeng atau juga disebut wayang wong adalah pertunjukan dengan para penari yang semuanya memakai topeng, sedang antawecana dilakukan dalang (1986: 97). Pengertian masalah wayang topeng, Suryodiningrat memberikan uraianya dalam bahasa Jawa:

Ingkang kawastanan ringgit Tiyang Topeng, ringgit tiyang ingkang sarana mawi topeng, kadamel saking kajeng randhu-wana lan kemiri, kasungging, kaprada la nisi pasemon, mboten beda kaliyan ringgit wacucal (1975: 1).

Terjemahan :

Yang disebut wayang orang topeng ialah wayang orang menggunakan alat (topeng) yang terbuat dari kayu randu hutan dan kayu kemiri, kemudian disungging, diberi warna keemasan agar terkesan hidup, agar tidak jauh berbeda dengan wayang kulit.

Informasi lain terkait hal ini, bahwa pasa zaman Mataram pertunjukan topeng sudah tersebar di seluruh pesisir yang meliputi pesisir utara, serta bagian barat dan timur daerah kejawen (Pigeaud, 1991: 48). Pati sebagai wilayah pesisir utara termasuk salah satu daerah penyebaran wayang topeng. Pertunjukan Wayang Topeng yang berada di Dukuh Kedungpanjang diperkirakan sudah ada sejak tahun 1896. Keterangan tentang asal usul wayang topeng di Kedungpanjang selama ini berdasarkan dari pelaku wayang topeng secara turun temurun. Salah satu sumber yang dapat digunakan sebagai pegangan dalam penelitian ini adalah keterangan dari Suharso selaku ketua grub wayang topeng. Menurut Suharso Pertunjukan Wayang Topeng muncul sekitar tahun 1896 dan tidak diketahui secara pasti pencipta dari Pertunjukan Wayang Topeng.

Pertunjukan Wayang Topeng mengalami 3 periode kepemimpinan. Mulai dari Suro Bungkik kemudian Sucat, dan dilanjutkan Sadipo yang merupakan satu keturunan. Pertunjukan ini rutin dipentaskan pada upacara bersih desa. Unsur pendukung Pertunjukan Wayang Topeng terdiri dari dalang, penyimping, penari, dan pengrawit. Pendukung berjumlah sekitar 24 orang yang merupakan penduduk asli Desa Soneyan. Warga mempercayai jika yang memainkan bukan warga asli, pemain itu akan kesulitan bahkan tidak bisa sesuai dengan Pertunjukan Wayang Topeng yang semestinya (Suharso, wawancara 30 April 2017).

Struktur sajian Wayang Topeng Dusun Kedungpanjang dibagi menjadi tiga bagian yaitu, bagian awal terdiri dari tari Prasonto dan tari Nembe, bagian inti yang merupakan isi cerita, dan bagian akhir sajian tari Pratajaya dan tari Kelana. Pada dasarnya pelaksanaan pola-pola gerak tari pada Wayang Topeng di Kedungpanjang terkesan sederhana, misalnya bentuk tanjak kaki yang dilakukan dengan kaki lurus atau berdiri. Dalam pelaksanaan pementasan khususnya penari putri, walaupun memakai topeng tetapi tetap menggunakan rias bedak dan lipstik. Busana Pertunjukan Wayang Topeng memiliki ciri khas yaitu dengan busana yang sederhana, namun perbedaan karakter yang 
diperankan tetap muncul, dan dapat menunjukan karakter wayang. Susunan musik dalam penyajian Wayang Topeng terdiri tari Prasonto menggunakan gendhing Bajing Loncat, tari Nembe menggunakan gendhing Wani-Wani, tari Pratajaya menggunakan gendhing Bedatan dan tari Kelana menggunakan gendhing Ginenjong. Adapun Gendhing yang digunakan dalam pathet nem ialah gendhing ganggong dan gendhing setra, pathet sanga menggunakan gendhing Sinom Parijatha dan Pathet manyura menggunakan gendhing bedatan dan gendhing ukluk.

Pertunjukan Wayang Topeng mempunyai potensi untuk diteliti salah satunya pertunjukan ini merupakan pertunjukan yang langka di kota Pati. Grup wayang topeng Klana Jaya Dukuh Kedungpanjang merupakan satu satunya di Kota Pati. Pertunjukan ini mampu bertahan di kalangan masyarakat Pati. Selain itu, Pertunjukan Wayang Topeng dalam penyajiannya terdiri dari unsur-unsur dialog, ada-ada, cerita, tema, penari, gerak, busana, dan musik. Misalnya pada unsur dialog, dalam pertunjukan ini mulai dari awal sajian sampai akhir sajian dilakukan oleh dalang, hal ini berbeda dengan wayang topeng Klaten dan Magelang. Ciri khas lain dapat dilihat dari musik tari, dalam pertunjukan ini terdapat surak takam yang diartikan oleh warga setempat yaitu sorak sorai dari pengiring yang diikuti penonton ketika mendapat ajakan dari dalang, hal ini dilakukan untuk menghidupkan suasana pertunjukan. Selain itu terdapat ciri khas lain pada musik Wayang Topeng yaitu bentuk tabuhan khas srepeg ukluk (Suharso, wawancara 30 April 2017).
Selain dilihat dari bentuk pertunjukan yang memiliki ciri khas, penulis tertarik dengan antusias masyarakat ketika melakukan apresiasi terhadap Pertunjukan Wayang Topeng. Secara suka rela mereka bergotong royong ikut mempersiapkan Pertunjukan Wayang Topeng. Adapun pada waktu pementasan semua masyarakat Dukuh Kedungpanjang datang untuk menyaksikan dari awal sajian hingga akhir sajian.

Pembahasan Pertunjukan Wayang Topeng ini akan difokuskan pada konsep munculnya Pertunjukan Wayang Topeng, koreografi Pertunjukan Wayang Topeng, dan tanggapan masyarakat mengenai Pertunjukan Wayang Topeng. Sesuai dengan fokus dari pembahasan, penelitian ini menggunakan suatu pendekatan kritik holistik karena dianggap mampu membahas Pertunjukan Wayang Topeng secara menyeluruh. Menurut H.B Sutopo, pendekatan ini dianggap paling lengkap karena memandang suatu karya, program, atau peristiwa dan kondisi tertentu, kualitasnya harus dipandang dari perspektif latar belakangnya (faktor genetik), kondisi formal yang berupa kenyataan objektifnya (faktor objketif), dan hasil atau dampaknya (output, product, outcome) yang juga meliputi presepsi orang yang berinteraksi dengan program atau karya yang dievaluasi tersebut (faktor afektif). Simpulan dari model ini dilakukan dengan analisis yang menghasilkan sintesis dari informasi lengkap yang bersumber dari tiga faktor tersebut. Tidak ada satu pun faktor yang memiliki otoritas (posisi yang paling penting) sebagai satu-satunya penentu nilai dalam kritik holistik (Sutopo, 2006: 143-144). 
FAKTOR GENETIK KEMUNCULAN PERTUNJUKAN WAYANG TOPENG

Sesuai dengan pemikiran H.B Sutopo mengenai faktor genetik yaitu latar belakang (faktor genetik), yang berupa segala hal yang berkaitan dan terjadi sebelum karya, konteks awalnya, sebelum program terwujud, dan juga proses pembentukannya (2006:144). Pembahasan mengenai faktor genetik lebih mengarah pada bagaimana latar belakang dari pertunjukan ini muncul. Faktor genetik dalam seni tari menurut Gotshalk (1996).

Faktor genetik terbagi menjadi dua yaitu faktor genetik yang bersifat subjektif dan faktor genetik bersifat objektif. Faktor genetik yang bersifat subjektif terdapat pada diri seniman. Sedangkan faktor genetik yang bersifat objektif merupakan kondisi iklim budaya lingkungan senimannya. Kedua faktor genetik baik yang bersifat subjektif maupun bersifat objektif merupakan satu kesatuan modal dasar seniman dalam membentuk, menentukan, dan menciptakan sebuah karya seni (Gotshalk dalam Maryono, 2015:117).

Faktor genetik yang bersifat subjektif memiliki bentuk genetik berupa konsep (gagasan dari karya seni yang dihasilkan), sedangkan faktor genetik yang bersifat objektif merupakan bentuk dari kondisi lingkungan seniman berada. Adapun faktor genetik yang bersifat objektif dan subjektif dalam Pertunjukan Wayang Topeng sebagai berikut.

\section{A. Faktor Genetik Objektif}

Faktor genetik yang bersifat objektif merupakan suatu faktor terbentuknya suatu karya seni yang dipengaruhi dan dibentuk dari kondisi iklim budaya lingkungan dimana seniman itu berada (Maryono, 2015: 119). Dalam Pertunjukan Wayang Topeng faktor genetik yang bersifat objektif terdapat pada iklim budaya Dukuh Kedungpanjang yaitu letak geografis Dukuh Kedungpanjang, Religi yang dipercayai oleh masyarakat, dan potensi pertunjukan yang berada di Desa Soneyan.

\section{Geografis}

Keadaan suatu daerah mempengaruhi suatu karya seni, seperti yang dikatakan R. Bintarto bahwa desa sebagai hasil perpaduan antara manusia dengan lingkungan, yang ditimbulkan atau dipengaruhi oleh unsur fisiografis, sosial, ekonomi, politik, dan cultural yang saling berinteraksi juga dalam hubungan dengan daerah lain (Bintarto, 1989: 11).

Dukuh Kedungpanjang terletak di Desa Soneyan Kecamatan Margoyoso Kabupaten Pati. Dukuh ini terletak di sebelah utara Kota Pati. Kondisi geografis Dusun Kedungpanjang adalah dataran tinggi dengan ketinggian 100 meter di atas permukaan air laut. Dusun Kedungpanjang termasuk daerah dengan tanah yang kering sehingga penduduk memanfaatkan ladang untuk melakukan kegiatan tani. Menurut data monografis dinamis, mata pencaharian penduduk Kedungpanjang sebagian besar sebagai petani. Bidang pertanian mendapatkan perhatian utama dalam pembangunan di Dukuh Kedungpanjang.

Dari uraian tersebut, keadaan geografis Dusun Kedungpanjang mempengaruhi konsep Pertunjukan Wayang Topeng yaitu pengambilan cerita Among Tani. Cerita Among Tani merupakan cerita carangan tentang percintaan Dewi Sri dan Wisnu yang dalam pengungkapannya 
mengenai simbol kesuburan dusun tersebut (Suharso, wawancara 21 Oktober 2017).

\section{Religi}

Mayoritas masyarakat Dukuh Kedungpanjang merupakan pemeluk agama Islam kejawen. Islam Kejawen merupakan wujud akulturasi dari agama Islam dan tradisi jawa. Hal ini sesuai dengan pernyataan Hariwijaya bahwa.

Agama Islam telah mengubah wajah dan kiblat orang Jawa. Namun, kuatnya tradisi Jawa membuat islam mau tak mau harus berakulturasi. Akhirnya, wujud akulturasi tersebut menjadi ajaran khas Jawa, yang dikenal dengan nama Islam Kejawen. Kini, Islam dan Kejawen hampir tidak dapat dipisahkan satu dengan lainnya. Kejawen menjadi warna baru yang berkembang di tanah Jawa (2006: 2).

Pengaruh Islam Kejawen masyarakat Kedungpanjang dapat dilihat dari beberapa upacara ritual atau Slamatan yang sampai sekarang tidak pernah ditinggalkan dalam tata cara kehidupan masyarakat. Mengenai upacara selamatan Clifford Geertz berpendapat bahwa Slametan adalah versi Jawa dari apa yang barangkali merupakan upacara keagamaan yang paling umum di dunia; ia melambangkan kesatuan mistis dan sosial mereka yang ikut serta di dalamnya(1981: 13). Upacara ritual yang dilakukan masyarakat Kedungpanjang diantaranya upacara bersih desa yang dilakukan satu tahun sekali pada bulan Apit hari Sabtu Kliwon yang mempunyai tujuan untuk mencapai tingkat keselamatan atau kesejahteraan.
Di samping itu, sebagian besar masyarakat masih melakukan kebiasaankebiasaan yang berkaitan dengan kepercayaan lama seperti kepercayaan pada kekuatan-kekuatan roh nenek moyang, pada benda-benda tertentu yang dianggap mempunyai kekuatan membantu dalam segi kehidupan. Di Dusun Kedungpanjang terdapat sebuah Kalangan (Punden) yang dipercayai sebagai tempat sakral. Pada saat tertentu masyarakat datang ke Punden membawa sesaji. Peristiwa tersebut dapat dilihat ketika diselenggarakan upacara sedekah bumi sebelum Pertunjukan Wayang Topeng di mulai, perlengkapan sesaji di letakan di Punden. Perlengkapan sesaji yang dimaksud antara lain pisang raja, bumbu wiwit, kupat lepet, ayam panggang, nasi buceng, dan telur. Selain itu terdapat ritual penyembelihan kambing yang dilakukan oleh perangkat desa pada bulan puasa dan bersih desa. Penyembelihan harus dilakukan di punden karena darah yang jatuh di punden merupakan inti dari ritual. Selain bersih desa terdapat Lamporan yaitu ritual yang dilakukan setiap bulan Suro hari Jumat Wage. Ritual Lamporan berbentuk arakarakan keliling Desa Soneyan dengan menampilkan kesenian yang ada, seperti wayang topeng, pencak dan Wayang Kulit. Dalam menampilkan masyarakat Soneyan membawa obor sebagai properti arakarakan.

Dari beberapa upacara rutin yang dilakukan di Desa Soneyan, hal ini membuktikan bahwa masyarakat Soneyan merupakan Islam Kejawen dan tidak mengherankan jika terdapat pertunjukan tradisi yang berupa Wayang Topeng yang dalam penyajiannya menggunakan sesaji dalam upacara bersih desa 
3. Potensi Pertunjukan Desa Soneyan

Desa Soneyan merupakan desa yang memiliki tiga dusun, yaitu Dusun Kedungpanjang, Dusun Clangap dan Dusun Sumber Soneyan. Masing-masing dusun memiliki pertunjukan yang berbeda dan tetap bertahan sampai sekarang. Dusun Clangap memiliki Pertunjukan Pencak dan dusun Sumber Soneyan terdapat Pertunjukan Wayang kulit. Pertunjukan-pertunjukan ini bertahan dan masih dipentaskan hingga sekarang. Hal ini dapat dilihat setiap bulan Apit dipentaskan sebagai ritual bersih desa (Suharso, wawancara 21 Oktober 2017).

Dalam berkesenian, masyarakat Desa Soneyan selalu guyup rukun dan saling bergotong royong artinya tidak ada rasa saling iri atau merasa paling menonjol. Antara Kesenian satu dengan yang lainnya saling mendukung contohnya ketika Pertunjukan Wayang Topeng ada pementasan, pengiring dari Pertunjukan Pencak dan Pertunjukan Wayang Kulit ikut membantu begitu juga sebaliknya.

Kerukunan masyarakat Desa Soneyan yang saling mendukung adalah salah satu kelebihan dari desa ini, sehingga berbagai pertunjukan dapat tumbuh dan bertahan hingga sekarang dengan baik tanpa adanya persaingan yang merusak. Salah satunya Pertunjukan Wayang Topeng yang berada di Kedungpanjang. Dengan dukungan dari pertunjukan di dusun lain, Pertunjukan Wayang Topeng tetap bertahan sampai sekarang. Selain itu pengaruh dari Pertunjukan Wayang Kulit terhadap bentuk Pertunjukan Wayang Topeng dapat terlihat dari bentuk pathetan. Bentuk pathet nem, pathet sanga, dan pathet manyura yang terdapat dalam Pertunjukan Wayang Topeng merupakan pengaruh dari Pertunjukan Wayang Kulit.

\section{B. Faktor Genetik Subjektif}

Faktor genetik yang bersifat subjektif adalah berupa konsep atau gagasan yang menyertai setiap karya seni (Maryono, 2015: 118). Sesuai dengan pemahaman di atas, faktor genetik yang bersifat subjektif muncul gagasan atau konsep dari Suharso. Suharso merupakan seniman yang bertanggung-jawab atas Pertunjukan Wayang Topeng. Hal ini dapat dipahami karena pencipta dari Pertunjukan Wayang Topeng tidak diketahui. Suharso memiliki beberapa konsep perubahan yaitu konsep perubahan busana dan perubahan masuknya unsur dagelan.

\section{Perubahan Busana}

Busana dalam Pertunjukan Wayang mengalami perubahan dari waktu kewaktu, yang ditentukan oleh seniman warga Desa Soneyan. Sebelum masa kepemimpinan Suharso, busana untuk tokoh laki-laki menggunakan celana panjang hitam dilengkapi dengan jarik dan sabuk otok (sabuk yang besar yang dimiliki orang tua di Desa Soneyan), iket, kaos, sumping yang terbuat dari kertas dan jali-jali yang disusun, gelang terbuat dari menjalin. Tokoh perempuan menggunakan jarik panjang, kebaya, jamang dan kain penutup rambut, sumping yang terbuat dari kertas dan jali-jali yang disusun, gelang terbuat dari menjalin. Sedangkan sekarang, busana yang digunakan masing-masing tokoh berbeda, dan disesuai dengan peran. Contoh busana pada tokoh Prabu Badokbasu menggunakan irah-irahan, sumping, kalung kace, klat bahu, sabuk, epek timang, jarek, sampur, celana 
bludru, gelang, topeng. Tokoh Dewi Sri menggunakan busana, irah-irahan, topeng, sumping, kebaya, sampur, slepe, boro samir, jarik.

Perubahan ini dilakukan agar Pertunjukan Wayang Topeng menjadi lebih menarik, dan agar digemari oleh masyarakat. Menurut Suharso dengan adanya perubahan bentuk busana pada pemain, akan mempermudah masyarakat menangkap cerita karena dengan perbedaan kostum yang dipakai oleh tokoh sebagai tanda peran yang ditampilkan oleh pemain (Suharso, Wawancara 13 Januari 2018).

\section{Perubahan Adegan Dagelan}

Struktur sajian Pertunjukan Wayang Topeng pada awalnya terdiri dari tari Prasonto, tari Nembe, cerita Among Tani, tari Pratajaya dan tari Kelana. Artinya dalam struktur purtunjukan yang dulu hanya terdiri dari tari ekstra dan cerita Amon Tani. Namun Sekarang oleh Suharso pada pertengahan adegan sebelum masuk ekstra tari Pratajaya terdapat Dagelan. Dagelan yaitu suatu lelucon yang dilakukan oleh seseorang. Dalam Pertunjukan ini dilakukan oleh pelawak ketoprak Pati yaitu Puput dan Rulilah.

Penambahan dagelan ini dilakukan agar Pertunjukan Wayang Topeng mengikuti jaman. Artinya mengikuti selera masyarakat sekarang yang mengharapkan adanya lelucon dalam suatu pertunjukan. Selain itu penambahan Dagelan sebagai hiburan dan untuk memperpanjang waktu pertunjukan. Menurut Suharso semakin lama pertunjukan semakin bagus. (Suharso, wawancara 13 Januari 2018).

\section{FAKTOR OBJEKTIF PERTUNJUKAN WAYANG TOPENG}

Faktor objektif menurut H.B Sutopo dalam buku Penelitian Kualitatif Dasar Teori dan Terapanya dalam Penelitian bahwa kondisi formal yang ada secara objektif (faktor objektif), yang berupa segala hal yang terjadi dan bisa ditangkap dengan indra pada karya, peristiwa, atau program yang sedang dievaluasi (2006: 144). Pernyataan H.B Sutopo mengenai faktor objektif ialah segala sesuatu yang bisa ditangkap dengan indra ketika melakukan apresiasi terhadap suatu karya merupakan bentuk dari karya itu.

Untuk membahas mengenai bentuk Wayang Topeng menggunakan pengertian "bentuk" dari Maryono dalam buku Analisa Tari bahwa bentuk adalah perpaduan dari beberapa unsur atau komponen yang bersifat fisik, saling mengikat dan terintegrasi dalam suatu kesatuan (Maryono: 2015 24). Sedangkan dalam upaya memperoleh gambaran secara utuh mengenai Pertunjukan Wayang Topeng penulis membedah lagi menjadi komponen verbal dan nonverbal. Komponen verbal merupakan komponen yang bersifat kebahasaan sedangkan komponen nonverbal adalah komponen yang bersifat non kebahasaan. Adapun wujud aktualisasinya dalam bentuk Pertunjukan Wayang Topeng, komponen verbal berupa: Ada-ada, dialog, janturan, dan tembang. Sedangkan komponen nonverbal terdiri dari tema, gerak, penari, rias busana, musik, panggung, properti, dan pencahayaan.

\section{Tema}

Tema dalam tari merupakan rujukan cerita yang dapat menghantarkan seseorang pada pemahaman esensi. Tema dapat ditarik dari sebuah peristiwa atau cerita, yang 
selanjutnya dijabarkan menjadi alur cerita sebagai kerangka sebuah garapan (Maryono, 2015: 52). Pada Pertunjukan Wayang Topeng menggunakan tema percintaan antara Dewi Sri dan Wisnu yang merupakan simbol kesuburan Dusun Kedungpanjang. Struktur sajian Wayang Topeng Dusun Kedungpanjang dibagi menjadi tiga bagian yaitu bagian awal terdiri dari tari Prasonto dan tari Nembe, bagian inti yang merupakan isi cerita, dan bagian akhir dengan sajian tari Protojoyo dan tari Kelana. Tari Prasonto dan tari Nembe merupakan tari ekstra yang digunakan sebagai pembukaan. Kedua tari ini tidak masuk dalam alur cerita. Tari Prasonto menggambarkan tokoh Kamandana dan Kamandanu. Sedangkan tari Nembe menggambarkan dua tokoh alus dan dua punakawan. Gerak yang digunakan adalah gerak-gerak dengan motivasi berdandan atau merias diri. Bagian inti yang merupakan isi cerita. Cerita yang disajikan Pertunjukan Wayang Topeng adalah cerita Among Tani yang bercerita tentang percintaan DewiSri dan Wisnu. Bagian akhir dengan sajian tari Protojoyo dan Tari Kelana. Kedua tari ini merupakan tari ekstra yang masuk ke dalam cerita atau cerita. tari Protojoyo merupakan penggambaran dari Resi Sarasjati dan Paman Protojoyo. Sedangkan tari Kelana menggambarkan Prabu Pabokbasu dan Togok.

\section{Penari}

Penari adalah seorang seniman yang menyajikan keindahan gerak tubuhnya dengan melibatkan daya tafsir dari estetik pada sebuah koreografi maupun imajinya (Tasman, 2008:27). Penari dalam Pertunjukan Wayang Topeng menyajikan keindahan gerak mereka sesuai dengan daya tafsir serta imaji dari masing-masing penari, daya tafsir serta imaji akan berpengaruh kepada peran yang dibawakan.

Pertunjukan Wayang Topeng sebagai pertunjukan rakyat yang hidup dan berkembang di Dusun Kedungpanjang terdiri dari limabelas penari. Menurut Bapak Suharso, Ketua dari grup Klana Jaya menyatakan bahwa penari Wayang Topeng harus keturunan dari penari Pertunjukan Wayang Topeng yang terdahulu. Dipercaya jika yang menjadi penari bukan dari warga Dusun Kedungpanjang, penari tersebut akan kesulitan dalam memainkan Pertunjukan Wayang Topeng, baik dari kesulitan dalam bergerak dan memainkan karakter topeng.

Selain penari, Pertunjukan Wayang Topeng didukung oleh sepuluh pengrawit, satu swarawati, seorang penyimping dan seorang dalang. Dalang merupakan seorang yang mengatur jalanya cerita mulai dari awal hingga akhir sajian. Selain itu dalang Wayang Topeng juga melakukan semua dialog penari, walaupun demikian suasana pertunjukan tetap hidup. Dalang yang berada di Kedungpanjang merupakan satu garis keturunan mulai dari Suro Bungkik, Surat dan Sadipo.

\section{Gerak}

Gerak dalam Pertunjukan Wayang Topeng sebenarnya sudah memiliki cukup banyak variasi, walaupun apabila dilihat secara keseluruhan bentuknya masih tetap sederhana serta terdapat pengulangan gerak yang memang merupakan ciri tari rakyat.

Dalam menganalisis gerak pada Pertunjukan Wayang Topeng menggunakan pendapat dari Soedarsono yang menyatakan bahwa secara garis besar jenis-jenis gerak dalam tari dapat dibedakan menjadi dua 
kelompok, yaitu gerak representasional dan gerak nonrepresentasional. "Gerak tari representasional adalah gerak tari yang menggambarkan sesuatu secara jelas, sedangkan gerak non representasional adalah gerak tari yang tidak menggambarkan sesuatu" (1978: 22). Berdasarkan dengan gagasan Soedarsono mengenai gerak representasional dan gerak non representasional akan digunakan untuk mengkaji jenis-jenis gerak yang terdapat dalam Pertunjukan Wayang Topeng. Adapun gerak non representasional yaitu gerak penghubung dan gerak peralihan. Sedangkan gerak representasional yaitu gerak pokok yang terdiri dari mbenake sabuk, mbenake klat bahu, mbenake sumping, mbenake irah-irahan, ngilo,dan mbenake sampur.

\section{Rias dan busana}

Dalam pelaksanaan pementasan khususnya penari putri walaupun memakai topeng tetapi tetap menggunakan rias bedak dan lipstik. Bentuk busana Pertunjukan Wayang Topeng memiliki ciri khas yaitu bagaimana dengan busana yang sederhana namun perbedaan karakter yang akan diperankan penari itu tetap muncul dan dapat menunjukan karakter Wayang.

Berikut busana yang digunakan masing-masing tokoh:

a. Kala Mambang : irah-irahan, sumping, kalung kace, kotang (rompi), klat bahu, sabuk, epek timang, jarek, sampur, celana bludru, gelang, topeng.

b. Temanggung kala derbo : Topeng, gimbalan, kalung kace, sabuk, jarek, celana panjang polos.

c. Temanggung kala Prasetyo: Topeng, gimbalan, kalung kace, sabuk, jarek, celana panjang polos. d. Batara Siwa : Irah irahan, sumping, topeng, kalung kace, slempang, sampur, sabuk, epek timang, jarek, celana.

e. Batara Sambu : Irah irahan, sumping, topeng, kalung kace, slempang, sampur, sabuk, epek timang, jarek, celana.

f. Batara Guru : irah irahan, sumping, topeng, kalung kace, kotang, klat bahu, sabuk, epek timang, jarek, sampur, celana pendek.

g. Dewi Sri : irah irahan, sumping, topeng, kebaya, sampur, slepe, jarik, boro samir.

h. Sri Sadono: irah irahan, sumping, topeng, kebaya, sampur, slepe, jarik, boro samir.

i. Sri Pinanthi : irah irahan, sumping, topeng, kebaya, sampur, slepe, jarik, boro samir.

j. Semar:Iket, topeng, kalung kace, sampur, kotang, sabuk, epektimang, gelang, celana, sampur.

k. Wisnu : irah irahan, topeng, sumping, kalung ulur, slempang, klat bahu, sabuk, epek timang, sampur, gelang, celana.

1. Resi Sarasjati : irah irahan, topeng, sumping, kalung kace, klat bahu, sabuk, epek timang, sampur, jarek, celan bludru, keris.

m. Paman Protojoyo : iket, topeng, sampur, kalung kace, kotang, sabuk, epek timang, sampur, jarek, celana.

n. Prabu Badokbasu: Irah irahan, sumping, topeng, kalung ulur, slepe, sampur, keris, sabuk, epek timang, jarek, gelang, celana.

o. Togok : Iket, topeng, sampur, kotang, gelang, sabuk, sampur, celana panjang.

\section{Topeng}

Fungsi dari topeng yaitu sebagai pengganti rias atau penutup muka yang mengekspresikan tokoh-tokoh dalam cerita yang ditampilkan. Menurut jenisnya topeng 
yang digunakan di Kedungpanjang dapat dibedakan menjadi dua, yaitu topeng yang menutup seluruh wajah dan topeng yang menutup sebagian wajah. Topeng yang menutup seluruh wajah cara penggunaanya dengan menggigit sekat terbuat dari kulit yang letaknya dibalik bibir topeng (topeng cokotan) contohnya topeng yang digunakan oleh tokoh utama seperti Prabu Badokbasu, Patih Kalamambang, Buto Kaladembo, Buto Kalamuka,Wisnu, Dewi Sri, Batara Narada, Batara Siwah, Batara Sambu, Sri Pinanthi, Sri Sardono dan Resi Sarasjati. Sedangkan topeng yang menutup sebagian wajah cara menggunakannya dengan mengikat tali ke belakang telinga (mengikat dua utas tali pada kepala bagian belakang). Topeng tersebut dipakai untuk tokoh-tokoh gecul seperti Semar, Gareng, Petruk, Paman Protojoyo dan Togok.

\section{Musik}

Musik merupakan bagian yang penting dalam sebuah pertunjukan tari, hal ini didukung oleh pernyataan La Merri terjemahan Soedarsono mengenai musik bahwa:

Dalam suatu pertunjukan, faktor musik tari tidak kalah pentingnya dengan faktor lain. Musik dan tari mempunyai hubungan yang sangat erat. Keduannya berasal dari sumber yang sama, yaitu dorongan atau naluri ritmis manusia (1966: 44)

Musik dalam Pertunjukan Wayang Topeng mengunakan laras slendro yang terbagi dalam tiga bagian pokok yaitu ; pathet nem, pathet sanga dan pathet manyura. Ricikan gamelan yang digunakan dalam Wayang Topeng menggunakan 11 ricikan diantaranya; Kendang, Bonang Barung, Bonang Penerus, Peking, Gambang, Saron, Demung, Gong, Slentem, Kenong, Keprak.

Dalam penyajian Wayang Topeng, gendhing yang digunakan, diantaranya :

a. Tari Prasonto, menggunakan gendhing Bajing Loncat

b. Tari Nembe, menggunakan gendhing Wani-Wani

c. Cerita

1). Pathet nem : gendhing ganggong dan gendhing Setra

2). Pathet sanga: gendhing Sinom Parijatha

3). Pathet manyura: gendhing bedatan dan gendhing Ukluk

d. Tari Pratajaya, menggunakan gendhing Bedatan

e. Tari Kelana, menggunakan gendhing Ginenjong

7. Panggung atau tempat Pertunjukan

Tempat Pertunjukan Wayang Topeng diselenggarakan di dua tempat yang berbeda yaitu kalangan (punden) dan depan rumah kepala desa. Kalangan yaitu tempat yang digunakan oleh masyarakat sekitar untuk berkumpul dan bermusyawarah. Bentuk dari kalangan ini berupa rumah kecil dengan dinding tembok dan atap dari asbes. Ketika untuk pertunjukan Wayang Topeng, tempat ini dihias dengan menggunakan daun kelapa( janur) dan balon. Menurut Bapak Suharso hiasan yang digunakan hanya berfungsi untuk mengias artinya tidak ada maksud atau tujuan yang lebih (Suharso, wawancara 21 Oktober).

Pada malam hari pentas Wayang Topeng dilaksanakan di halaman rumah kepala desa. di depan rumah kepala desa berdiri bangunan yang digunakan untuk 
pementasan, biasa disebut tarub. Tarub terbagi menjadi dua bagian, bagian pertama untuk panggung dan bagian kedua untuk penonton. Panggung masih dibagi menjadi tiga lagi, samping kiri untuk pengrawit, kanan depan untuk pertunjukan tari, dan kanan belakang untuk persiapan penari.

\section{Pencahayaan}

Pertunjukan Wayang Topeng Desa Soneyan merupakan pertunjukan rakyat yang biasa dipentaskan di panggung terbuka, baik malam hari maupun siang hari. Pada awalnya, pertunjukan Wayang Topeng hanya menggunakan lampu petromaks sebagai penerangan, namun sekarang menggunakan lampu general ketika pentas malam hari.

\section{FAKTOR AFEKTIF TANGGAPAN TERHADAP PERTUNJUKAN WAYANG TOPENG}

Faktor afektif merupakan tanggapan dari penghayat atau penonton terhadap karya seni. Penghayat terjadi apabila penghayat dapat menangkap keseluruhan intensionalitas yang terdapat dalam karya tari (Widyastutiningrum, dkk, 2007: 6). Adapun tanggapan terhadap pertunjukan ini muncul dari beberapa Seniman dan masyarakat.

Tanggapan muncul dari masyarakat Dusun Kedung panjang yaitu Sawi, Tono, Harti. Selain itu juga muncul tanggapan dari Seniman yaitu Sajo, Suharso, dan Darma. Dari wawancara di atas dapat dirangkum sebagai berikut. Pertama Pertunjukan Wayang Topeng merupakan bentuk drama tari dengan menggunakan topeng dengan tema percintaan antara Dewi Sri Dan Wisnu. Percintaan antara Dewi Sri dan wisnu di dalam cerita Among Tani memiliki makna sebagai simbol kesuburan desa. Kedua kehadiran Pertunjukan Wayang Topeng di tengah-tengah masyarakat Dukuh Kedungpanjang Desa Soneyan merupakan pertunjukan yang wajib di pentaskan pada waktu bersih desa. Masyarakat mempercayai dengan diadakan Pertunjukan Wayang Topeng masyarakat hidup sejahtera dan selamat.

\section{PENUTUP}

Pertunjukan Wayang Topeng Dukuh Kedungpanjang, Desa Soneyan Kecamatan Margoyoso, Kabupeten Pati merupakan bentuk pertunjukan drama tari dengan mengambil cerita Among Tani. Cerita Inti dari among Tani menceritakan tentang kisah percintaan antara Dewi Sri dan Wisnu. Bagi masyarakat Soneyan, cerita percintaan antara Dewi Sri dan Wisnu merupakan simbol kesuburan. Fungsi utama Pertunjukan Wayang Topeng digunakan sebagai sarana upacara selamatan bersih desa. Pertunjukan Wayang Topeng disajikan selama sekitar lima jam, pada setiap bulan Apit yaitu antara bulan Besar Duri pada hitungan bulan Jawa. Pertunjukan Wayang Topeng dilaksanakan di Punden desa Soneyan yang disebut Kalangan. Masyarakat melaksanakan serangkaian upacara selamatan bersih desa dengan menyajikan Kesenian Wayang Topeng secara substansi digunakan sebagai syarat untuk keselamatan dan kesejahteraan seluruh masyarakat Desa Soneyan. Keselamatan yang dimaksud ialah masyarakat hidup ayem tentrem, tidak ada musibah ataupun malapetaka yang akan terjadi di Desa Soneyan, sedangkan Kesejahteraan yang dimaksud iyalah kelancaran pangan, hasil panen melimpah. 
Munculnya Pertunjukan dalam masyarakat tidak lepas dengan faktor genetik, faktor objektif dan faktor afektif. Demikian juga bentuk Pertunjukan Wayang Topeng di Dusun Kedungpanjang. Masyarakat Kedungpanjang sebagian besar bermata pencaharian sebagai petani. Hal ini mempengaruhi cerita pertunjukan Wayang Topeng, yang disajikan dengan mengambil cerita Among Tani. Masyarakat Kedungpanjang merupakan Islam Kejawen dan tidak mengherankan jika terdapat pertunjukan tradisi yang berupa Wayang Topeng yang berfungsi sebagai upacara bersih desa dengan menggunakan berbagai sesaji.

Struktur sajian pertunjukan secara utuh terdiri dari; bagian awal tari Prasonto dan tari Nembe, bagian inti yang sajian Wayang Topeng dengan cerita Among Tani, dan bagian akhir sajian tari Protojoyo, dan tari Kelana. Dalam sajian Wayang Topeng menggunakan unsur- unsur dialog, tembang, ada- ada, janturan, tema, penari, gerak, rias dan busana, musik.

Secara umum masyarakat Desa Soneyan menangkap dan memaknai Pertunjukan Wayang Topeng. Hampir semua masyarakat mengerti tentang cerita yang disajikan, serta memahami makna yang terkandung di balik cerita. Seniman bersama masyarakat terus melestarikan Wayang Topeng dengan melakukan regenerasi pemain, perubahan bentuk sajian yang semuanya untuk ketentraman, damai bagi masyarakat.

\section{DAFTAR PUSTAKA}

Ensiklopedi Tari.

1986. Ensikklopedi Tari Indonesia. Jakarta:

Proyek Inventarisasi dan Dokumentasi Kebudayaan Daerah, Departemen Pendidikan dan Kebudayaan.

Geertz, Hildred.

1981. Aneka Budaya dan Komunitas di Indonesia. Jakarta: Yayasan Ilmu-ilmu Sosial FIS - UI.

Hariwijaya.

2006. Islam Kejawen. Yogyakarta: Gelombang Pasang.

La Meri.

1986. Elemen-elemen Dasar Komposisi Tari, Soedarsono. Yogyakarta: Lagaligo.

Maryono.

2015. Analisa Tari. Surakarta: Isi Press.

Pigeaud.

1991. Pertunjukan Rakyat Jawa. Surakarta: Reksa Pustaka Agung.

R. Bintarto.

1989. Interagsi Desa - Kota dan Permasalahanya. Jakarta: Ghalia Indonesia.

Soedarsono.

1972. Djawa dan Bali Dua Pusat Perkembangan Drama Tari Tradisional di Indonesia. Yogyakarta: Gadjah Mada University Press.

Suryodiningrat.

1975. Ringgit Tiyang Topeng. Yogyakarta: Tanpa Penerbit.

Sutopo, H.B.

1995. Kritik Seni Holistik Sebagai Model Pendekatan Penelitian Kualitatif Pengukuhan Guru Besar. Surakarta: Sebelas Maret University Press. 


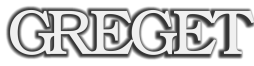

2006. Metedologi Penelitian Kualitatif. Surakarta: Universitas Negri Sebelas Maret.

Tasman.
2008. Analisa gerak dan karakter. Surakarta: ISI Press.

Widyastutieningrum, Sri Rochana, dkk.

2007. Kritik Tari. Surakarta:Institut Seni Indonesia. 